Int. J. Electrochem. Sci., 12 (2017) $9288-9300$

\title{
A Novel Flakes-Like Structure of Molybdenum Disulphide Modified Glassy Carbon Electrode for the Efficient Electrochemical Detection of Dopamine
}

\author{
Rajalakshmi Sakthivel ${ }^{1}$, S. Dhanalakshmi ${ }^{2}$, Shen-Ming Chen ${ }^{1, *}$, Tse-Wei Chen $^{1}$, V. Selvam ${ }^{2}$, \\ Sayee Kannan Ramaraj ${ }^{3}$, Wen-Hui Weng ${ }^{1,4,}$, , Wai-Hung Leung ${ }^{5,}$ * \\ ${ }^{1}$ Department of Chemical Engineering and Biotechnology, National Taipei University of Technology, \\ No. 1, Section 3, Chung-Hsiao East Road, Taipei 106, Taiwan, Republic of China. \\ ${ }^{2}$ Department of Chemistry, VHNSN College, Virudhunagar - 626001, Tamilnadu, India. \\ ${ }^{3}$ PG \& Research department of Chemistry, Thiagarajar College, Madurai 09, Tamilnadu, India \\ ${ }^{4}$ Graduate Institute of Biochemical and Biomedical Engineering, National Taipei University of \\ Technology, Taipei City 106, Taiwan, R.O.C. \\ ${ }^{5}$ Division of Colorectal Surgery, Department of Surgery, Mackay Memorial Hospital, Taipei City 104, \\ Taiwan, R.O.C. \\ *E-mail: smchen78@ms15.hinet.net wendywwh@ntut.edu.tw leungwh22@gmail.com
}

doi: $10.20964 / 2017.10 .71$

Received: 19 June 2017 / Accepted: 11 August 2017 / Published: 12 September 2017

In this present study, we have reported a novel and simple hydrothermal approach for synthesis of molybdenum disulphide $\left(\mathrm{MoS}_{2}\right)$ flakes. The synthesized material effectively utilized for the fabrication dopamine electrochemical sensor. Moreover, the successful formation of flakes-like $\mathrm{MoS}_{2}$ was confirmed by X-ray diffraction (XRD), scanning electron microscope (SEM) and energy dispersive Xray $(\mathrm{EDX})$ studies. The electrochemical characteristics of the flakes-like $\mathrm{MoS}_{2}$ were studied by using cyclic voltammograms (CVs) and amperometric ( $i-t)$ techniques. As an electrochemical sensor, the flakes-like $\mathrm{MoS}_{2}$ modified glassy carbon electrode (GCE) exhibited higher electrocatalytic activity in the oxidation of dopamine in terms of higher oxidation peak current and lower oxidation potential when compared with bare GCE. The flakes-like $\mathrm{MoS}_{2}$ based electrochemical sensor has been fabricated which detect dopamine in wide linear response range $(0.006-181 \mu \mathrm{M})$, good sensitivity

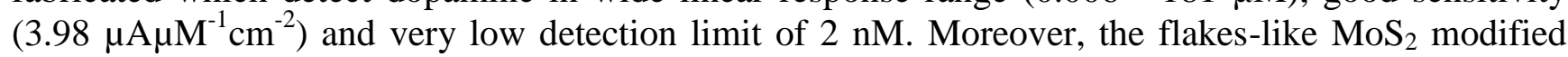
GCE showed good selectivity even in the presence of biologically co-interfering compounds and common metal ions.

Keywords: Flakes-like structure, $\mathrm{MoS}_{2}$, SEM, Electrochemical sensor, Dopamine

FULL TEXT 
(C) 2017 The Authors. Published by ESG (www.electrochemsci.org). This article is an open access article distributed under the terms and conditions of the Creative Commons Attribution license (http://creativecommons.org/licenses/by/4.0/). 